University of South Carolina

Scholar Commons

2000

\title{
Moderate Intensity Exercise Training Improves Cardiorespiratory Fitness in Women
}

\author{
J. David Branch \\ Russell R. Pate \\ University of South Carolina - Columbia, rpate@mailbox.sc.edu \\ Sharon P. Bourque
}

Follow this and additional works at: https://scholarcommons.sc.edu/

sph_physical_activity_public_health_facpub

Part of the Public Health Commons

\section{Publication Info}

Published in Journal of Women's Health \& Gender-Based Medicine, Volume 9, Issue 1, 2000, pages 65-73. Branch, J. D., Pate, R. R., \& Bourque, S. P. (2000). Moderate intensity exercise training improves cardiorespiratory fitness in women. Journal of Women's Health \& Gender-Based Medicine, 9(1), 65-73. DOI: $10.1089 / 152460900318984$ (C) Journal of Women's Health \& Gender-Based Medicine, 2000, Mary Ann Liebert, Inc.

This Article is brought to you by the Physical Activity and Public Health at Scholar Commons. It has been accepted for inclusion in Faculty Publications by an authorized administrator of Scholar Commons. For more information, please contact digres@mailbox.sc.edu. 


\title{
Moderate Intensity Exercise Training Improves Cardiorespiratory Fitness in Women
}

\author{
J. DAVID BRANCH, Ph.D., ${ }^{1}$ RUSSELL R. PATE, Ph.D., ${ }^{2}$ and SHARON P. BOURQUE, Ph.D. ${ }^{3}$
}

\begin{abstract}
Among women, there is an increased prevalence of sedentary lifestyle and less participation in physical activity at levels recommended by the Surgeon General. As a result, women have been identified as a target group in public health initiatives to increase physical activity. The health-related benefits of habitual, moderate intensity physical activity are well documented in the epidemiological literature, but less is known about the effect of such physical activity on cardiorespiratory fitness. Our hypothesis was that moderate and vigorous exercise training regimens of similar estimated energy expenditure would result in similar changes in cardiorespiratory fitness. Eighteen sedentary premenopausal women with the following baseline characteristics $[\bar{x} \pm \mathrm{SE}]$ : maximal oxygen consumption $\left(\dot{\mathrm{V}}_{2} \mathrm{max}\right)=29.5 \pm 1.5 \mathrm{ml} \cdot \mathrm{kg}^{-1}$. $\min ^{-1}$; age $=33 \pm 1$ years; height $=162.6 \pm 0.9 \mathrm{~cm} ;$ mass $=62.7 \pm 2.3 \mathrm{~kg}$, were randomly assigned to either vigorous $\left(\mathrm{HI}, 80 \% \dot{\mathrm{Vo}}_{2} \mathrm{max}, n=10\right)$ or moderate intensity (MOD, $40 \% \dot{\mathrm{Vo}}_{2} \mathrm{max}$, $n=8)$ cycle ergometer training groups. Exercise training was conducted $3-4(3.37 \pm 0.05)$ days/week for 12 weeks in a supervised and progressive manner, with estimated exercise energy expenditure equated across both training groups. $\dot{\mathrm{V}}_{2} \mathrm{max}$ and time to exhaustion increased significantly in both groups $(p<0.05)$, with no difference between groups. Both groups had lower $(p<0.05)$ posttraining submaximal heart rates $(H R)$, respiratory exchange ratios (RER), and ratings of perceived exertion (RPE) during graded exercise testing, with no significant differences between the groups in posttraining values. Women participating in moderate intensity exercise training as recommended in basic public health guidelines demonstrate an increase in cardiorespiratory fitness similar to that elicited by vigorous training.
\end{abstract}

\section{INTRODUCTION}

$\mathbf{M}$ AINTENANCE OF A PHYSICALLY ACTIVE LIFESTYLE is known to provide numerous health benefits, including reduced risk for development of chronic diseases, such as coronary heart disease (CHD), ${ }^{1-4}$ diabetes mellitus, ${ }^{5}$ hypertension, ${ }^{6,7}$ colon cancer, ${ }^{8,9}$ and osteoporosis, ${ }^{10}$ as well as re- duced risk of death from all causes. ${ }^{6,11,12}$ Accordingly, for over three decades, authorities in medicine, public health, and education have endorsed regular physical activity as an effective method for promoting health and preventing disease. ${ }^{13-16}$ Traditional physical activity guidelines have tended to emphasize the importance of structured, vigorous exercise, ${ }^{13,17}$ and such

${ }^{1}$ Department of Exercise Science, Physical Education, and Recreation, Old Dominion University, Norfolk, Virginia.

${ }^{2}$ Department of Exercise Science, University of South Carolina, Columbia, South Carolina.

${ }^{3}$ Department of Health, Physical Education, and Recreation, University of North Carolina-Wilmington, Wilmington, North Carolina. 
guidelines are supported by a large number of controlled exercise training studies that demonstrated that regular performance of continuous, vigorous exercise (e.g., jogging for 30-45 minutes 3 or more days per week) produces significant increases in maximal oxygen consumption $\left(\mathrm{V}_{2}\right.$ max $) .{ }^{18-25}$

More recent public health recommendations on physical activity, including that from the U.S. Surgeon General, ${ }^{26}$ have endorsed daily participation in moderate intensity physical activity. ${ }^{15,16}$ Support for these guidelines has been drawn primarily from the findings of epidemiological studies demonstrating the beneficial effects of accumulated, moderate intensity physical activity on chronic disease risk. ${ }^{11,12,27-33}$

There are two important issues pertaining to these public health recommendations. First, it has been reported that most women are sedentary, with only a small percentage of women of various ethnic backgrounds participating in levels of physical activity recommended by the Surgeon General or engaged in vigorous physical activity. ${ }^{34-36}$ Second, there is a lack of knowledge concerning the potential effects of such physical activity on cardiorespiratory fitness. ${ }^{37,38}$ The scientific literature includes relatively few controlled exercise training studies examining the physiological effects of regular participation in moderate intensity physical activity. This gap in the literature may slow acceptance of current public health recommendations on physical activity among certain professional groups and segments of the public. Specifically, improved cardiorespiratory fitness in women following moderate intensity exercise training may facilitate acceptance by women of habitual moderate intensity activity for improvement of both health and fitness. To address this deficiency in the scientific literature, the present study compared the metabolic and cardiorespiratory effects of moderate intensity and vigorous intensity exercise training in women.

\section{MATERIALS AND METHODS}

\section{Subjects}

Subjects were part of previously published investigations of the effects of mode and intensity of exercise on hematological adaptation ${ }^{39,40}$ and iron status. ${ }^{41}$ Healthy, nonsmoking 20-40-year- old women were recruited via newspaper advertisements and direct mailings and were screened for participation. Inclusionary criteria included eumenorrhea ( $\geq 9$ menstrual cycles in the last 12 months), no pregnancy in the last 12 months, and no regular exercise in the last 6 months. Subjects were sedentary at baseline, with no participation in habitual physical activity, and were self-described as either "professional/clerical worker" $(76 \%)$, "student" (12\%), or "homemaker" (12\%). All potential subjects were apprised of the experimental procedures and gave informed consent in accordance with the Human Subjects Review Committee, School of Public Health, University of South Carolina.

\section{Research design}

Subjects were randomly assigned to either moderate intensity (MOD) or vigorous intensity (HI) training groups and completed a 12-week progressive exercise training program at $40 \%$ and $80 \%$ of initial individual $\mathrm{VO}_{2}$ max, respectively. Oxygen consumption $\left(\dot{\mathrm{V}}_{2}\right)$, ventilation $(\dot{\mathrm{VE}})$, respiratory exchange ratio (RER, ratio of carbon dioxide produced/oxygen consumed $\left(\dot{\mathrm{V}}_{\mathrm{CO}} /\right.$ $\dot{\mathrm{V}}_{2}$ ), heart rate (HR), time to exhaustion, and rating of perceived exertion (RPE) were measured during graded maximal exercise before and after training. Testing and training was performed using cycle ergometry. Subjects reported to the laboratory between 0600 and 1100 hours (0830 \pm 0110 hours). All exercise test data were collected following a 10-12-hour fast at least 36 hours after the last exercise session.

\section{Anthropometric measures}

Body mass, height, and triceps, suprailiac, and anterior thigh skinfold measurements were recorded before and after the training period. Skinfold measurements were used to estimate pretraining and posttraining body density, ${ }^{42}$ with subsequent estimate of body fat percentage. ${ }^{43}$

\section{Metabolic measures}

$\dot{\mathrm{V}}_{2} \mathrm{max}$ was measured at baseline and following training using a Monark 818 cycle ergometer. The cycle ergometer protocol began with a work rate of $25 \mathrm{~W}\left(1 \mathrm{~W}=6.12 \mathrm{~kg} \cdot \mathrm{min}^{-1}\right)$, increasing $25 \mathrm{~W}$ every 2 minutes for the first 6 minutes and every minute thereafter. Each subject was verbally encouraged to give her best effort until vo- 
litional fatigue. HR was measured from electrocardiographic (ECG) recordings. Each subject was asked to evaluate her perception of effort during each stage using the original (category 620) Borg RPE scale. ${ }^{44} \dot{\mathrm{V}}_{2}\left(1 \cdot \mathrm{min}^{-1}\right)$, $\dot{\mathrm{O}}_{\mathrm{E}}(1 \cdot$ $\left.\min ^{-1}\right)$, and RER were measured at 15 -second intervals by open circuit, indirect calorimetry. ${ }^{45} \mathrm{An}$ on-line system (Rayfield, Inc., Chicago, IL) was used, consisting of a Parkinson-Cowan CD-4 volume meter and Applied Electrochemistry CD-3A and S-3A/1 $\mathrm{CO}_{2}$ and $\mathrm{O}_{2}$ analyzers, calibrated against a Tissot tank and standard gas mixtures, respectively. Criteria for attainment of $\dot{\mathrm{V}}_{2}$ max were $R E R \geq 1.1$ and an increase in oxygen consumption of no more than $2 \mathrm{ml} \cdot \mathrm{kg}^{-1} \cdot \mathrm{min}^{-1}$ with the final increase in work rate. ${ }^{45}$ At least one of these criteria was met for both tests in all subjects.

\section{Exercise training}

Training was conducted indoors in a well-ventilated, climate-controlled area and was carefully monitored by the investigators in accordance with American College of Sports Medicine guidelines. ${ }^{17}$ Subjects were provided fluids ad libitum. Training dose was increased progressively, beginning at an estimated $628 \mathrm{~kJ} \cdot$ session $^{-1}(150$ $\mathrm{kcal} \cdot \operatorname{session}^{-1}$, week 1), increasing to $837 \mathrm{~kJ}$. session $^{-1}\left(200 \mathrm{kcal} \cdot\right.$ session $\left.^{-1}\right)$ in week 2 and by $105 \mathrm{~kJ} \cdot \operatorname{session}^{-1} \cdot$ week $^{-1}\left(25 \mathrm{kcal} \cdot\right.$ session $^{-1}$. week $^{-1}$ ) thereafter until week 9 . From week 9 to the completion of training, estimated energy expenditure remained at $1560 \mathrm{~kJ} \cdot$ session $^{-1}(375$ $\mathrm{kcal} \cdot$ session $^{-1}$ ). Intensity was higher in the HI group, whereas duration was longer in the MOD group, resulting in similar total training volumes. Exercise HR was monitored and maintained within 5 beats $\cdot \min ^{-1}$ of the HR associated with $40 \%$ or $80 \%$ of baseline $\dot{\mathrm{O}}_{2}$ max. As training pro- gressed, workrate was increased $5 \pm 2(\bar{x} \pm$ SD) times to maintain the desired training HR range.

\section{Statistical analysis}

Effects of training on $\dot{\mathrm{V}}_{2}, \mathrm{HR}, \mathrm{RER}$, and RPE were analyzed by repeated measures ANOVA. ${ }^{46}$ Exercise training variables, including sessions attended, estimated metabolic equivalents (METs) $\left(1 \mathrm{MET}=3.5 \mathrm{ml} \cdot \mathrm{kg}^{-1} \cdot \mathrm{min}^{-1}\right), \mathrm{HR}$, exercise $\mathrm{du}-$ ration $\cdot \operatorname{session}^{-1}$, and $\mathrm{kJ} \cdot \mathrm{kg}^{-1} \cdot \mathrm{min}^{-1}$, were also analyzed by repeated measures ANOVA. ${ }^{46}$ An $\alpha$ level of 0.05 was used for main (group and trial) effects and interaction effects, with a Bonferroni adjustment for post hoc comparisons. Unless otherwise indicated, all values are $\bar{x} \pm$ SE.

\section{RESULTS}

\section{Baseline physical characteristics}

The results are based on 18 of 23 subjects $(78 \%)$ who completed the study. As shown in Table 1, groups were similar in such physical characteristics as age, height, mass, and $\dot{\mathrm{V}}_{2}$ max. Subjects who discontinued their participation (3 HI, 2 MOD) had baseline values for age (33 \pm 3 years), body mass index (BMI) $\left(25 \pm 1.1 \mathrm{~kg} \cdot \mathrm{m}^{-2}\right)$, and $\dot{\mathrm{V}}_{2} \max \left(29.7 \pm 2.4 \mathrm{ml} \cdot \mathrm{kg}^{-1} \cdot \mathrm{min}^{-1}\right)$ that were not significantly different from those who completed the study. Lack of time for training (3 subjects), family problems (1 subject), and pregnancy (1 subject) were reasons for failing to complete the study.

\section{Exercise training}

Subjects completed a total of 728 exercise sessions, $605(83.1 \%)$ of which were directly moni-

Table 1. Baseline Physical Characteristics $(\bar{x} \pm$ SE) of Subjects

\begin{tabular}{lcc}
\hline & \multicolumn{2}{c}{ Group $^{\mathrm{a}}$} \\
\cline { 2 - 3 } & $\begin{array}{c}\text { MOD } \\
\text { Variable }\end{array}$ & $\begin{array}{c}H I \\
(\mathrm{n}=8)\end{array}$ \\
\hline Age (years) & $32 \pm 2$ & $33 \pm 2$ \\
Height $(\mathrm{cm})$ & $162.8 \pm 1.6$ & $162.5 \pm 0.9$ \\
Mass $(\mathrm{kg})$ & $65.7 \pm 3.6$ & $60.2 \pm 2.7$ \\
Estimated body fat $(\%)$ & $24.7 \pm 1.6$ & $22.8 \pm 2$ \\
VO & max $\left(1 \cdot \mathrm{min}^{-1}\right)$ & $1.96 \pm 0.15$ \\
$\dot{V}_{2} \max \left(\mathrm{ml} \cdot \mathrm{kg}^{-1} \cdot \mathrm{min}^{-1}\right)$ & $1.74 \pm 0.14$ & $29.2 \pm 2.4$ \\
\hline
\end{tabular}

${ }^{a}$ There were no significant differences for any variable between groups. 
tored by the investigators. There was no difference between the HI and MOD groups in number of sessions completed. Summary data on exercise intensity, duration, frequency, and progression are presented in Table 2. According to the study design, mean exercise HR, exercise intensity (METs), estimated rate of energy expenditure $\left(\mathrm{kJ} \cdot \mathrm{kg}^{-1} \cdot \min ^{71}\right)$, and exercise duration $\left(\min \cdot \operatorname{session}^{-1}\right)$ differed between the two groups $(p<0.05)$. However, training volume was similar in the two groups, and there were no withinweek intergroup differences in estimated energy expenditure.

\section{Effects of exercise training on body mass and} estimated percentage of body fat

Body mass for HI (pre $=60.2 \pm 2.9 \mathrm{~kg}$, post $=$ $60.1 \pm 2.9 \mathrm{~kg}$ ) and MOD (pre = 65.7 $\pm 3.8 \mathrm{~kg}$, post $=67.7 \pm 4.2 \mathrm{~kg}) \quad$ was not significantly changed during the study. There was also no significant change in sum of triceps, suprailiac, or anterior thigh skinfold measurements. Thus, es- timated percentage of body fat was similarly unchanged for HI (pre $=26.3 \pm 2.1 \%$, post $=26.3 \pm$ $2.4 \%$ ) and MOD (pre $=29.5 \pm 1.7 \%$, post $=$ $29.1 \pm 1.6 \%$ ) subjects, respectively.

\section{Effects of exercise training on cardiorespiratory response to workrates of 25-175 W}

The effects of high and moderate intensity training regimens on $\dot{\mathrm{V}}_{2}, \mathrm{HR}$, and RER during workrates of $25-175 \mathrm{~W}$ are presented in Figure 1. All subjects in both groups completed pretraining and posttraining workrates of 25,50 , and 75 W. Pretraining and posttraining workrates of 100 , 125,150 , and $175 \mathrm{~W}$ were completed by $10,10,7$, and 5 subjects in the HI group, respectively, and $7,6,6$, and 6 subjects in the MOD group completed these workrates. HR at 100, 125, 150, and $175 \mathrm{~W}$ were decreased in both $\mathrm{HI}$ and MOD groups following training compared with baseline $(p<0.05)$, with no difference between training groups. RER was lower in both groups after training at workrates of 50,75, 100, 125, 150, and

Table 2. Exercise Training Intensity, Duration, Frequency, Progression, and Estimated Energy Expenditure in Moderate and Vigorous Training Groups $(n=18)^{\mathrm{a}}$

\begin{tabular}{|c|c|c|}
\hline \multirow[b]{2}{*}{ Variable } & \multicolumn{2}{|c|}{ Group } \\
\hline & $\begin{array}{c}M O D \\
(\mathrm{n}=8)\end{array}$ & $\begin{array}{c}H I \\
(\mathrm{n}=10)\end{array}$ \\
\hline \multicolumn{3}{|l|}{ Exercise intensity } \\
\hline HR & $133 \pm 4^{*}$ & $155 \pm 3$ \\
\hline $\mathrm{MET}^{\mathrm{b}}$ & $4.4 \pm 0.3^{*}$ & $6.8 \pm 0.4$ \\
\hline Estimated $\mathrm{kJ} \cdot \mathrm{kg}^{-1} \cdot \min ^{-1}$ & $0.31 \pm 0.04^{*}$ & $0.51 \pm 0.10$ \\
\hline $\mathrm{kcal} \cdot \mathrm{kg}^{-1} \cdot \min ^{-1}$ & $0.07 \pm 0.005^{*}$ & $0.12 \pm 0.007$ \\
\hline $\bar{x}$ work rate & $60 \pm 3^{*}$ & $90 \pm 8$ \\
\hline \multicolumn{3}{|l|}{ Exercise duration } \\
\hline Min $\cdot \operatorname{session}^{-1}$ & $61.9 \pm 4^{* *}$ & $39.4 \pm 4$ \\
\hline \multicolumn{3}{|l|}{ Exercise frequency and adherence } \\
\hline Sessions $\cdot$ week $^{-1}$ & $3.3 \pm 0.2$ & $3.4 \pm 0.3$ \\
\hline Total exercise sessions & $40 \pm 2$ & $41 \pm 3$ \\
\hline \multicolumn{3}{|l|}{ Exercise progression } \\
\hline Initial work rate & $45 \pm 6^{*}$ & $93 \pm 32$ \\
\hline End of training work rate & $75 \pm 10^{*}$ & $103 \pm 23$ \\
\hline Increments in work rate (number) & $6 \pm 2^{* *}$ & $4 \pm 2$ \\
\hline \multicolumn{3}{|l|}{ Estimated energy expenditure } \\
\hline$\overline{\mathrm{x}} \mathrm{kJ} \cdot \operatorname{session}^{-1}$ & $1242 \pm 1.5$ & $1243 \pm 1.4$ \\
\hline$\overline{\mathrm{x}} \mathrm{kcal} \cdot$ session $^{-1}$ & $292 \pm 4$ & $291 \pm 4$ \\
\hline
\end{tabular}

${ }^{a}$ Values are $\mathrm{x} \pm \mathrm{SE}$ across all 12 weeks of training.

${ }^{\mathrm{b}} \mathrm{MET}$, multiple of resting metabolic rate of $3.5 \mathrm{ml} \cdot \mathrm{kg}^{-1} \cdot \mathrm{min}^{-1} \cdot 1 \mathrm{kcal}=$ $4.186 \mathrm{~kJ}$.

${ }^{*} \mathrm{HI}>\mathrm{MOD}, p \leq 0.05$.

${ }^{* *} \mathrm{MOD}>\mathrm{HI}, p \leq 0.05$. 

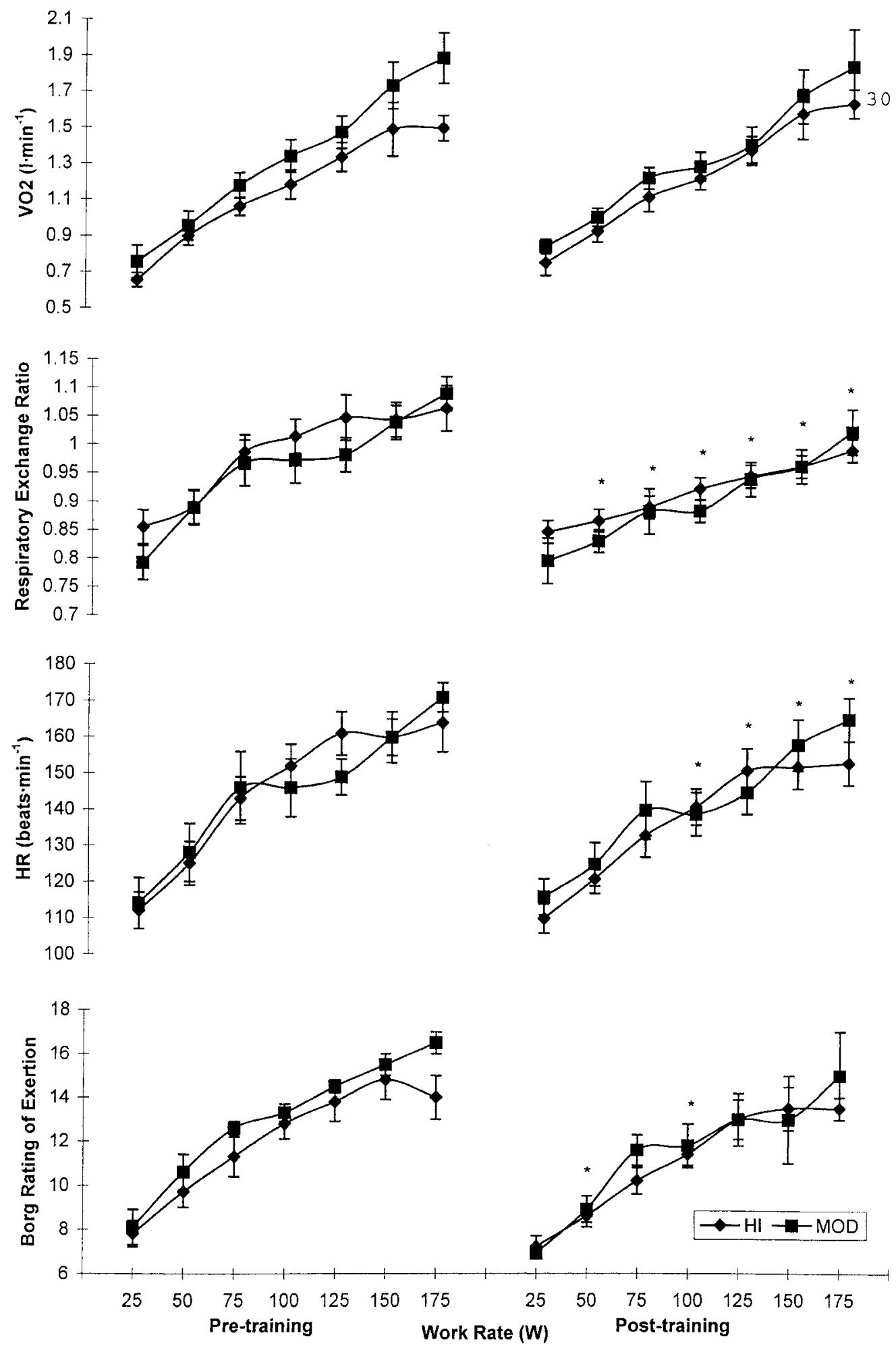

FIG. 1. Effect of high and moderate intensity training on $\dot{\mathrm{VO}}_{2}$, RER, HR, and Borg RPE at workrates at 25-175 W. ${ }^{*}$ Posttraining $<$ pretraining for both groups, with no difference between groups, $p \leq 0.05$. 
$175 \mathrm{~W}(p \leq 0.05)$, with no difference between training groups.

\section{Maximal exercise}

The effects of vigorous and moderate intensity training regimens on $\dot{\mathrm{V}}_{2}$ max and RERmax have been reported previously. ${ }^{40}$ Briefly, $\dot{V}_{2}$ max $\left(1 \cdot \mathrm{min}^{-1}\right)$ increased significantly $(p<0.05)$ following training for both groups $(\mathrm{MOD}=17 \%$, $\mathrm{HI}=21 \%$ ), with no significant difference in improvement between the groups. Time to exhaustion increased by $19 \%$ (569 \pm 49 seconds to $677 \pm$ 56 seconds) and $23 \%(599 \pm 38$ seconds to $736 \pm$ 37 seconds) for the MOD and HI groups, respectively $(p<0.05)$. $\dot{\mathrm{V}}_{\mathrm{E}} \mathrm{max}$ also increased following training $(p<0.05)$ from $61 \pm 5.4$ to $71 \pm 6.61$. $\mathrm{min}^{-1}$ (MOD) and $56.6 \pm 6$ to $68.5 \pm 4.1 \cdot \mathrm{min}^{-1}$ (HI). Maximal HR was not changed by either high or moderate intensity training.

\section{RPE during submaximal and maximal exercise}

The effects of exercise training at $40 \%$ and $80 \%$ of $\dot{\mathrm{V}}_{2}$ max on RPE during submaximal exercise are also shown in Figure 1. Both training groups showed decreased RPE at $50 \mathrm{~W}$ and $100 \mathrm{~W}$ compared with baseline $(p<0.05)$. Maximal RPE remained unchanged in both groups $(\mathrm{HI}=$ $15 \pm 1$ to $16 \pm 1 ; \mathrm{MOD}=15 \pm 1$ to $16 \pm 1$ ).

\section{DISCUSSION}

To our knowledge, this study is the first to examine the cardiorespiratory adaptations following training at the extremes of the recommended range of exercise intensity $(40 \%$ versus $80 \%$ of $\dot{\mathrm{V}}_{2}$ max) $)^{13}$ in premenopausal women over 21 years of age. The key finding of the present study, in which training intensity, duration, frequency, and energy expenditure were well controlled, progressive, and monitored by the investigators, was that the lower HR, RER, and RPE observed at workrates of 25-175 W after 12 weeks of regular participation in moderate intensity physical activity were similar to the decreases in these variables following high intensity exercise training. These changes indicate similar improvements in cardiorespiratory efficiency (HR) and energy substrate use (RER) in the two groups. The increases in cardiorespiratory fitness and time to exhaustion following moderate intensity training were similar to the increases in these variables following high intensity training. It is noteworthy that the increase in cardiorespiratory fitness following training at $80 \%$ of $\mathrm{VO}_{2} \max (21 \%)$ was neither proportionally nor significantly greater than the increase observed following training at $40 \%$ of $\dot{\mathrm{VO}}_{2} \max (17 \%)$. Thus, the results of this study provide important information concerning the relationship between exercise intensity and improvement in cardiorespiratory fitness. This finding suggests that in women who are relatively unfit to begin with, moderate intensity physical activity can provide much of the potential improvement in cardiorespiratory fitness that accompanies aerobic exercise training at higher intensities. Furthermore, this finding is important because it documents that the moderate intensity physical activity endorsed in recent public health pronouncements can enhance physical fitness in women as well as provide long-term health benefits.

Demographic data indicate that most women are sedentary, with only a small percentage $(\sim 13 \%)$ from various ethnic backgrounds involved in physical activity as recommended by the Surgeon General. ${ }^{26,36-38}$ According to data from the Behavioral Risk Factor Surveillance System, only $6.2 \%$ of women younger than 44 years of age were classified as "regularly active, intensive" ( $\geq 3$ sessions $\cdot \mathrm{wk}^{-1}, \geq 20 \mathrm{~min} \cdot \mathrm{session}^{-1}, \geq 60 \%$ of maximal cardiorespiratory capacity). In addition, the only group with no decrease in the prevalence of physical inactivity from 1986 $(25.2 \%)$ to $1990(25.8 \%)$ was $18-29$-year-old women. ${ }^{47}$ One possible interpretation of these physical activity demographic data is that, in women, vigorous, intense activity may be less well received than moderate activity. If this is indeed the case, our finding of the efficacy of moderate intensity training in improving cardiorespiratory fitness has public health implications in this population.

Our finding that moderate intensity exercise training improved cardiorespiratory fitness is in agreement with the results of the small number of other studies that examined exercise intensities below $50 \%$ of $\dot{\mathrm{V}}_{2}$ max..$^{20,48,49}$ Duncan et al. ${ }^{48}$ reported increases in $\dot{\mathrm{V}}_{2}$ max of $4 \%, 9 \%$, and $16 \%$, respectively, in young women who walked 4.8 $\mathrm{km}$ five times $\cdot$ week $^{-1}$ at either $4.8,6.4$, or $7.0 \mathrm{~km}$ $\cdot \mathrm{h}^{-1}$ for 24 weeks. These walking velocities represented $\sim 37 \%$ ("strollers"), $\sim 45 \%$ ("brisk walkers"), and $\sim 50 \%$ ("aerobic walkers") of baseline 
$\dot{\mathrm{V}}_{2} \mathrm{max}$, respectively. "Strolling" and "brisk walking" resulted in significant improvements in $\dot{\mathrm{V}}_{2}$ max compared with a sedentary control group. Gossard et al. ${ }^{20}$ reported an $8 \%$ improvement in $\dot{V}_{2}$ max in male subjects following 12 weeks of walk/jog exercise training 5 days . week ${ }^{-1}$ at an HR range of $102-120$ beats $\cdot \mathrm{min}^{-1}$ $\left(\sim 42 \%-60 \%\right.$ of $\left.\dot{\mathrm{V}}_{2} \mathrm{max}\right)$. Gaesser and $\mathrm{Rich}^{49}$ reported a $17 \%$ improvement in $\dot{\mathrm{V}}_{2}$ max in male subjects following 18 weeks of cycle ergometer training 3 days $\cdot$ week $^{-1}$ at $45 \%$ of $\dot{\mathrm{V}}_{2}$ max. The available literature appears to be consistent regarding the efficacy of moderate intensity training in improving cardiorespiratory fitness. The $17 \%$ improvement in $\dot{\mathrm{V}}_{2} \max \left(1 \cdot \mathrm{min}^{-1}\right)$ observed in this study is comparable to the increases reported in these studies.

Three previous studies $20,49,50$ have compared cardiorespiratory adaptations following training at the extremes of the currently recommended intensity range of $40 \%-85 \%$ of $\dot{\mathrm{V}}_{2}$ max. In the present study, training volume was sufficient to result in similar increases in $\dot{\mathrm{V}}_{2} \mathrm{max}$ in the $\mathrm{HI}$ and MOD groups. Gaesser and $\mathrm{Rich}^{49}$ reported improvements of $19.6 \%$ and $17.2 \%$ in $\mathrm{V}_{2}$ max of male subjects following high $(80 \%-85 \%$ of $\left.\dot{\mathrm{V}}_{2} \mathrm{max}\right)$ and low $\left(45 \%\right.$ of $\left.\dot{\mathrm{V}}_{2} \mathrm{max}\right)$ respectively, intensity, cycle ergometer training 3 days $\cdot$ week $^{-1}$ for 18 weeks. In a study of college-aged women, Edward ${ }^{50}$ reported increases of $26 \%$ and $34 \%$ in $\dot{\mathrm{V}}_{2} \mathrm{max}$ following training regimens (5 days . week $^{-1}, 15 \mathrm{~min} \cdot$ session $^{-1}$ for 4 weeks) at HR of 125 beats $\cdot \min ^{-1}(64 \%$ of HRmax) and 145 beats $\cdot \min ^{-1}(75 \%$ of HRmax), respectively, despite the fact that total training volume was not controlled. Following a 12-week walking/jogging program (5 days - week ${ }^{-1}, 350 \mathrm{kcal} \cdot \mathrm{ses}^{-}$ sion $^{-1}$ ), Gossard et al. ${ }^{20}$ reported a $17 \%$ increase in $\dot{\mathrm{V}}_{2}$ max in a high intensity training group of male subjects (HR range $128-148 ; \sim 63 \%-81 \%$ of $\dot{\mathrm{V}}_{2} \mathrm{max}$ ), which was significantly greater than the $8 \%$ increase observed in a low intensity training group of male subjects (HR range 102-122; $\sim 42 \%-60 \%$ of $\dot{\mathrm{V}}_{2}$ max). Possible reasons for these discordant findings include differences in training frequency and duration, weekly exercise energy expenditure, and training mode, as well as differences in monitoring the intensities of training. Regardless, it appears possible that endurance exercise performed at $40 \%-50 \%$ of $\dot{\mathrm{V}}_{2}$ max for longer durations can elicit similar improvements in $\mathrm{VO}_{2} \max$ to endurance exercise training performed at $50 \%-85 \%$ of $\dot{\mathrm{V}}_{2}$ max for shorter durations. Although training intensity is a key determinant of improvement in cardiorespiratory fitness, it would seem that training volume, to which training intensity contributes, is also an important determinant of training adaptation.

A limitation of this investigation was the relatively small sample size, which may explain why the mean difference between HI and MOD in improvement in $\dot{\mathrm{V}}_{2} \max \left(21 \%\right.$ versus $17 \%, 1 \cdot \mathrm{min}^{-1}$; $21 \%$ versus $14 \%, \mathrm{ml} \cdot \mathrm{kg}^{-1} \cdot \mathrm{min}^{-1}$ ) was not found to be statistically significant. For $\dot{\mathrm{V}}_{2}$ max, the observed statistical power for the trial main effect was 0.95 , but it was only 0.43 for the group by trial interaction. We are aware that a difference between $\mathrm{HI}$ and MOD groups for $\dot{\mathrm{V}}_{2}$ max expressed in $\mathrm{ml} \cdot \mathrm{kg}^{-1} \cdot \mathrm{min}^{-1}$ would have been detected with a larger sample size and that a more pronounced effect of higher intensity training on $\dot{\mathrm{V}}_{2} \mathrm{max}$ is a likely outcome. It is also important to note that the $2.0 \mathrm{~kg}$ gain in the MOD group was due to increased mass in 2 subjects who increased absolute $\dot{\mathrm{V}}_{2} \max \left(1 \cdot \mathrm{min}^{-1}\right)$ by $17 \%$ but whose presence attenuated the increase $(14 \%)$ in relative $\dot{\mathrm{V}}_{2} \max \left(\mathrm{ml} \cdot \mathrm{kg}^{-1} \cdot \mathrm{min}^{-1}\right)$. However, a direct benefit of working with a small group of exercising subjects was our ability to carefully control training. Furthermore, the degree of precision in monitoring training intensity and total volume employed in this study would have been less feasible with a larger training group. It is recommended that future studies attempt to employ the careful monitoring employed in this study with larger groups of subjects.

The findings of the present study have important implications for physicians and other health professionals who are now being called on to counsel their patients or clients regarding physical activity. ${ }^{15}$ National surveys indicate that $<10 \%$ of U.S. adults participate regularly in vigorous physical activity, ${ }^{47}$ and beginning exercisers may adhere more successfully to programs that emphasize moderate intensity physical activity than those involving vigorous exercise. ${ }^{51}$ The findings of this study suggest that moderate intensity physical activity can produce substantial increases in cardiorespiratory fitness as well as reduce risk of developing cardiovascular and other chronic diseases. Hence, physicians can use protocols, such as Physician-Based Assessment and Counseling for Exercise (PACE), ${ }^{52}$ to recommend moderate intensity physical activity to patients with confidence that such activity will 
provide increased fitness in addition to reduce disease risk.

In conclusion, moderate intensity training elicited significant improvement in cardiorespiratory fitness in young women, a population that may be more receptive than young men to physical activity recommendations that include moderate intensity exercise. These data suggest that if training volume is held constant, a health-oriented training regimen of moderate intensity may elicit improvements in cardiorespiratory fitness that are similar to those in a higher intensity training regimen.

\section{ACKNOWLEDGMENTS}

We are indebted to Dr. Victor Convertino (formerly at Physiology Research Branch, Clinical Sciences Division, Brooks AFB, TX, and currently at the U.S. Army Institute of Surgical Research, Fort Sam Houston, TX) and the National Aeronautics and Space Administration (NASA) for lending us Monark cycle ergometers, which were used in exercise training.

\section{REFERENCES}

1. Cooper KH, Pollock ML, Martin RP, White SR, Linnerud AC, Jackson A. Physical fitness levels vs selected coronary risk factors: A cross-sectional study. JAMA 1976;236:166.

2. Ekelund L, Haskell WL, Johnson JJ, Whaley FS, Criqui FH, Sheps DS. Physical fitness as a predictor of cardiovascular mortality in asymptomatic North American men: The Lipid Research Clinics mortality follow-up study. N Engl J Med 1988;319:1379.

3. Leon AS, Connett J, Jacobs DR, Rauramaa R. Leisuretime physical activity levels and risk of coronary heart disease and death. The Multiple Risk Factor Intervention Trial. JAMA 1987;258:2388.

4. Powell KE, Thompson PD, Casperson CJ, Kendrick JS. Physical activity and the incidence of coronary heart disease. Annu Rev Public Health 1987;8:253.

5. Helmrich SP, Ragland DR, Leung RW, Paffenbarger RS. Physical activity and reduced occurrence of noninsulin-dependent diabetes mellitus. N Engl J Med 1991;1325:147.

6. Blair SN, Goodyear NN, Gibbons LW, Cooper KH. Physical fitness and incidence of hypertension in healthy normotensive men and women. JAMA 1984; 252:487.

7. Paffenbarger RS, Wing AL, Hyde RT, Jung DL. Physical activity and incidence of hypertension in college alumni. Am J Epidemiol 1983;117:245.
8. Gerhardsson M, Norell SE, Kiviranta H, Pederson NL, Ahlbom A. Sedentary jobs and colon cancer. Am J Epidemiol 1986;123:775.

9. Vena JE, Graham S, Zielezny M, Swanson MK, Barnes RE, Nolan J. Lifetime occupational exercise and colon cancer. Am J Epidemiol 1985;122:357.

10. Gutin B, Kasper MJ. Can vigorous exercise play a role in osteoporosis prevention? A review. Osteoporosis Int 1992;2:55.

11. Blair SN, Kohl HW, Paffenbarger RS, Clark DG, Cooper KH, Gibbons LW. Physical fitness and allcause mortality: A prospective study of healthy men and women. JAMA 1989;262:2395.

12. Paffenbarger RS, Hyde RT, Wing AL, Hsieh C. Physical activity, all-cause mortality, and longevity of college alumni. N Engl J Med 1986;314:605.

13. American College of Sports Medicine Position Stand. The recommended quantity and quality of exercise for developing and maintaining cardiorespiratory and muscular fitness and flexibility in healthy adults. Med Sci Sports Exerc 1998;30:975.

14. Fletcher GF, Blair SN, Blumenthal J, et al. Statement on exercise benefits and recommendations for physical activity programs for all Americans: A statement for health professionals by the Committee on Exercise and Cardiac Rehabilitation of the Council on Clinical Cardiology, American Heart Association. Circulation 1992;286:340.

15. Pate RR, Pratt M, Blair SN, et al. Physical activity and public health: A recommendation from the Centers for Disease Control and Prevention and the American College of Sports Medicine. JAMA 1995;273:402.

16. Physical activity and cardiovascular health. NIH Consensus Statement. Kensington, MD, 1995;13:1.

17. American College of Sports Medicine. Guidelines for exercise testing and prescription, 5th ed. Baltimore, MD: Williams \& Wilkins, 1995:153.

18. Atomi $Y$, Ito K, Iwasaki H, Miyashita M. Effects of intensity and frequency of training on aerobic capacity of young females. J Sports Med 1978;18:3.

19. Blair SN, Chandler JV, Ellisor DB, Langley T. Improving physical fitness by exercise training programs. South Med J 1980;73:1594.

20. Gossard D, Haskell WL, Taylor CB, et al. Effects of low- and high-intensity home based exercise training on functional capacity in healthy middle aged men. Am J Cardiol 1986;57:446.

21. Kearney JT, Stull A, Ewing JL, Strein JW. Cardiorespiratory responses of sedentary college women as a function of training intensity. J Appl Physiol 1976;41: 822.

22. Pollock ML, Ward A, Ayres JJ. Cardiorespiratory fitness: Responses to differing intensities and durations of training. Arch Phys Med Rehabil 1977;58:467.

23. Pollock ML, Dimmick J, Miller HS, Kendrick Z, Lunnerud AC. Effects of mode of training on cardiovascular function and body composition of adult men. Med Sci Sports 1975;7:139.

24. Pollock ML, Broida J, Kendrick Z, Miller HS, Janeway $\mathrm{R}$, Linnerud AC. Effects of training two days per week 
at different intensities on middle-aged men. Med Sci Sports 1972;4:192.

25. Pollock ML, Cureton TK, Greninger L. Effects of frequency of training on working capacity, cardiovascular function, and body composition of adult men. Med Sci Sports 1969;1:70.

26. Physical Activity and Health: A Report on the Surgeon General. 1996. U.S. Department of Health and Human Services. Centers for Disease Control and Prevention, National Center for Chronic Disease Prevention and Health Promotion, Atlanta, GA, 1996.

27. Blair SN, Kohl HW, Barlow CE, Paffenbarger RS, Gibbons LW, Macera CA. Change in physical fitness and all-cause mortality: A prospective study of healthy and unhealthy men. JAMA 1995;273:1093.

28. Montoye HJ. Physical activity and health: An epidemiologic study of an entire community. Englewood Cliffs, NJ: Prentice-Hall, Inc., 1975.

29. Paffenbarger RS, Hyde RT, Wing AL, Lee I, Jung DL, Kampert JB. The association of changes in physical activity level and other lifestyle characteristics with mortality among men. N Engl J Med 1993;328:538.

30. Paffenbarger RS, Hale WE. Work activity and coronary heart mortality. N Engl J Med 1975;292:545.

31. Sandvik L, Erikssen J, Thaulow E, Erikssen G, Mundal $\mathrm{R}$, Rodahl K. Physical fitness as a predictor of mortality among healthy, middle-aged Norwegian men. N Engl J Med 1993;328:533.

32. Siscovick DS, Weiss NS, Hallstrom AP, Inui TS, Peterson DR. Physical activity and primary cardiac arrest. JAMA 1982;248:3113.

33. Sobolski J, Kornitzer M, Backer GD, et al. Protection against ischemic heart disease in the Belgian Physical Fitness Study: Physical fitness rather than physical activity? Am J Epidemiol 1987;125:601.

34. Ransdell LB, Wells CL. Physical activity in urban white, African-American, and Mexican-American women. Med Sci Sports Exerc 1998;30:1608.

35. Jones DA, Ainsworth BE, Croft JB, Marera CA, Lloyd EE, Yusuf HR. Modrate leisure-time physical activity: Who is meeting the public health recommendations? A national cross-sectional study. Arch Fam Med 1998; $7: 285$.

36. Wilbur J, Miller AM, Montgomery A, Chandler P. Women's physical activity patterns: Nursing implications. J Obstet Gynecol Neonatal Nurs 1998;27:383.

37. Haskell WL. J.B. Wolffe Memorial Lecture. Health consequences of physical activity: Understanding and challenges regarding dose-response. Med Sci Sports Exerc 1994;26:649.

38. Pate RR. Physical activity and health: Dose-response issues. Res Q Exerc Sport 1995;66:313.

39. Branch JD, Pate RR, Bourque SP, Convertino VA, Durstine JL, Ward DS. Effects of exercise mode on hematologic adaptations to endurance training in adult females. Aviat Space Environ Med 1997;68:788.

40. Branch JD, Pate RR, Bourque SP, Convertino VA, Durstine JL, Ward DS. Exercise training and intensity does not alter vascular volume responses in women. Aviat Space Environ Med 1999;70:1070.

41. Bourque SP, Pate RR, Branch JD. Twelve weeks of endurance exercise training does not affect iron status measures in adult females. J Am Diet Assoc 1997;97: 1116.

42. Jackson AS, Pollock ML, Ward A. Generalized equations for predicting body density of women. Med Sci Sports Exerc 1980;12:175.

43. Siri WE. Body composition from fluid spaces and density: Analysis of methods. In: Techniques for measuring body composition. Washington, DC, National Academy of Sciences, 1961:223.

44. Borg GA. Psychological bases of perceived exertion. Med Sci Sports Exerc 1982;14:377.

45. Consolazio CF, Johnson RE, Pecora LJ. Physiological measurements of metabolic function in man. New York: McGraw-Hill Book Company, 1963:1, 375

46. SAS Institute, Inc., SAS/STAT® user's guide, Version 6, 4th ed. Cary, NC: SAS Institute, Inc. 1989;2:891.

47. Casperson CJ, Merritt RK. Physical activity trends among 26 states, 1986-1990. Med Sci Sports Exerc $1995 ; 27: 713$.

48. Duncan JJ, Gordon NF, Scott CB. Women walking for health and fitness. How much is enough? JAMA 1991; 266:3295.

49. Gaesser GA, Rich RG. Effects of high- and low-intensity exercise training on aerobic capacity and blood lipids. Med Sci Sports Exerc 1984;16:269.

50. Edwards MA. The effects of training at predetermined heart rate levels for sedentary college women. Med Sci Sport 1974;6:14.

51. Pollock ML. Prescribing exercise for fitness and adherence. In: Dishman RK, ed. Exercise adherence: Its impact on public health. Champaign, IL: Human Kinetics Publishers, 1988.

52. Long B, Wooten W, Patrick K, Calfas K, Sharpe D, Sallis J. Physician-Based Assessment and Counseling for Exercise (Project PACE) physician manual. Atlanta, GA: Centers for Disease Control, Cardiovascular Health Branch, 1992.

Address reprint requests to: J. David Branch, Ph.D., F.A.C.S.M. Assistant Professor

Department of Exercise Science, Physical Education, and Recreation Old Dominion University Norfolk, VA 23529-0196 